\title{
Additive Effects of Methyl Ketones in the Belousov-Zhabotinsky Reactions
}

\author{
Igal Berenstein and Daniel Barragán*
}

\author{
Laboratorio de Calorimetría y Dinámica Química No-Lineal (451-217), Departamento de Química, Facultad de \\ Ciencias, Universidad Nacional de Colombia, Bogotá, Colombia
}

\begin{abstract}
O papel das metil cetonas em reações oscilantes do tipo Belousov-Zhabotinsky (BZ) é eliminar bromo molecular através de um processo de enolização, mas sua importância na dinâmica da reação depende do composto orgânico usado como substrato. Este trabalho mostra que em uma mistura binária de metil cetonas , cada cetona age independentemente mas com efeito aditivo na dinâmica da reação. Os resultados obtidos estão apoiados em simulações baseadas nos mecanismos de ambas as reações.
\end{abstract}

The role of the methyl ketones in oscillating reactions of the Belousov-Zhabotinsky (BZ) type is to eliminate bromine through an enolization process, but its importance in the dynamic of the reaction depends upon the organic compound that is used as substrate. This work shows that in a binary mixture of methyl ketones every ketone acts independently, but with an additive effect in the dynamics of the BZ reaction. The results obtained are supported by numerical simulations based upon the mechanisms for both reactions.

Keywords: Belousov-Zhabotinsky reaction, methyl ketones, additive effects

\section{Introduction}

Oscillating chemical reactions, specially the BelousovZhabotinsky (BZ), ${ }^{1}$ have been studied under a great variety of conditions. ${ }^{2,3} \mathrm{~A}$ detailed study of the $\mathrm{BZ}$ reaction with oxalic acid and ketones, ${ }^{4}$ in a wide interval of concentrations of the main reactants and the ketones, allowed us to broaden the understanding of the mechanism that was given for this reaction. If the concentration of ketone is very low or it is very high, oscillations are inhibited because the concentration of $\mathrm{Br}_{2}$ will also be either very high or very low. In the same way, and contrary to what was thought, this oscillating reaction can exhibit an induction period that appears in an interval of concentration of acetone or in an interval of enolization constant (different types of methyl ketones).

This reaction, $\mathrm{BrO}_{3}^{-}-\mathrm{Ce}^{3+}-(\mathrm{COOH})_{2}-\mathrm{CH}_{3} \mathrm{COR}$, has a detailed mechanism proposed by Field and Boyd, ${ }^{5}$ that can be seen as the following three step global process:
A) $\mathrm{BrO}_{3}^{-}+5 \mathrm{Br}^{-}+6 \mathrm{H}^{+} \leftrightarrow 3 \mathrm{Br}_{2}+3 \mathrm{H}_{2} \mathrm{O}$
$\mathrm{CH}_{3} \mathrm{COR} \leftrightarrow \mathrm{CH}_{2}=\mathrm{COHR}$
$3 \mathrm{CH}_{2}=\mathrm{COHR}+3 \mathrm{Br}_{2} \rightarrow 3 \mathrm{BrCH}_{2} \mathrm{COR}+3 \mathrm{Br}^{-}+3 \mathrm{H}^{+}$
B) $5 \mathrm{H}^{+}+4 \mathrm{Ce}^{3+}+\mathrm{BrO}_{3}^{-} \rightarrow 2 \mathrm{H}_{2} \mathrm{O}+\mathrm{HOBr}+4 \mathrm{Ce}^{4+}$

* e-mail: dabarraganra@unal.edu.co

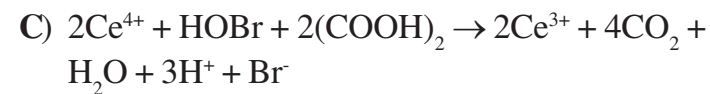

The global process $\mathbf{A}$ has the kinetic control of the reaction when the concentration of $\mathrm{Br}$ is high. The main way to obtain $\mathrm{Br}$, is the hydrolysis of $\mathrm{Br}_{2}$, through the reaction:

$$
\begin{aligned}
\mathrm{Br}_{2}+\mathrm{H}_{2} \mathrm{O} \leftrightarrow \mathrm{Br}+\mathrm{HOBr}+\mathrm{H}^{+} \quad & \mathrm{k}_{\text {forward }}=110 \mathrm{~s}^{-1}, \\
& \mathrm{k}_{\text {reverse }}=8.0 \times 10^{9} \mathrm{~mol} \mathrm{~L}^{-3} \mathrm{~s}^{-1} .
\end{aligned}
$$

Global process $\mathbf{B}$ takes control of the reaction, when the concentration of $\mathrm{Br}$ is low enough. The role of process $\mathbf{C}$ is to reduce $\mathrm{Ce}^{4+}$ ion via oxidation of oxalic acid. If this reaction is analyzed without the presence of ketones, oscillations are not predicted. The ketone in this reaction is the one that controls the concentration of $\mathrm{Br}_{2}$ in process $\mathbf{A}$.

The classic BZ reaction with malonic acid is the most widely studied oscillating reaction and it has a web developed mechanism. The FKN mechanism, ${ }^{6}$ which has 10 reactions, and the GTF mechanism, ${ }^{7,8}$ which has 80 reactions, can be generalized as a three step global process:

$$
\text { A') } \begin{aligned}
\mathrm{BrO}_{3}^{-}+5 \mathrm{Br}+6 \mathrm{H}^{+} \leftrightarrow 3 \mathrm{Br}_{2}+3 \mathrm{H}_{2} \mathrm{O} \\
\mathrm{CH}_{2}(\mathrm{COOH})_{2} \leftrightarrow \mathrm{HOOC}-\mathrm{CH}=\mathrm{C}(\mathrm{OH})_{2} \\
3 \mathrm{HOOC}_{2} \mathrm{CH}=\mathrm{C}(\mathrm{OH})_{2}+3 \mathrm{Br}_{2} \rightarrow 3 \mathrm{BrCH}(\mathrm{COOH})_{2}+ \\
3 \mathrm{Br}^{-}+3 \mathrm{H}^{+}
\end{aligned}
$$




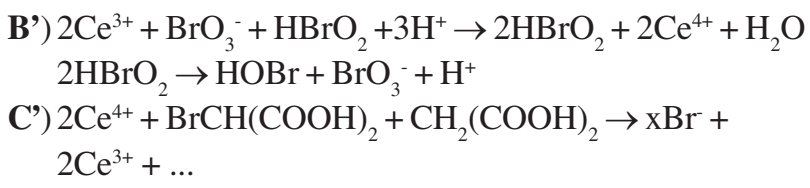

The BZ reaction in its oscillatory stages, alternates the kinetic control between process $\mathbf{A}^{\prime}$ and process $\mathbf{B}^{\prime}$. When the bromide concentration is high, process $\mathbf{A}^{\prime}$ takes place, and when is low, process $\mathbf{B}^{\prime}$ takes the kinetic control. Process $\mathbf{C}^{\prime}$ reduces cerium and produces $\mathrm{Br}$.

One of the main characteristics of the classic BZ reaction is an induction period before the oscillatory regime is achieved. Burger and Koros ${ }^{9}$ found experimentally that in this induction period the bromomalonic acid accumulates, until it reaches a crucial concentration and then the oscillations start. In a previous work ${ }^{10}$ we showed how this hypothesis was essentially correct, not by measuring bromomalonic acid, but by studying the effect of methyl ketones in the reaction. Methyl ketones are very suitable organic substrates because they do not react with bromate, cerium (IV) or any oxibrominated compound. ${ }^{5}$ Then the effect of methyl ketones in the $\mathrm{BZ}$ reaction with malonic acid is to modify, selectively, the kinetics of the global process $\mathbf{A}^{\prime}$, in which the bromomalonic acid is produced.

In this work it is shown that a binary mixture of methyl ketones in the BZ reaction with malonic acid and in the $\mathrm{BZ}$ reaction with oxalic acid, each of the ketones acts independently, but the total effect in the dynamics of the reaction is the sum of the individual effects.

\section{Experimental}

The BZ oscillators were studied under batch conditions in a cylindrical double-walled glass cell, $80 \mathrm{~mL}$ capacity, thermostated to $25.00 \pm 0.01{ }^{\circ} \mathrm{C}$ by circulating water through the internal wall of the cell. The solution was magnetically stirred from the bottom, at a frequency of about $250 \mathrm{rpm}$ avoiding the vortex formation. The reaction was followed with a platinum electrode with internal reference, Cole-Parmer 27006-21, connected to a multimeter Hewlett-Packard 3478A with sensitivity of $0.1 \mu \mathrm{V}$. Data acquisition was made through a GPIB IEEE488 interface.

The reagents used were: sulfuric acid (AnalytiCals Carlo Erba 96\%), oxalic acid dihydrate (Merck f.a), malonic acid (Merck f.a), cerium (III) nitrate hexahydrate (Merck ultrapure), potassium bromate (Mallinckrodt chemical works, recrystalized from sulfuric acid), acetone (Merck f.s), methyl-ethyl ketone (Merck f.s), methyl-propyl ketone (Merck f.s), methyl-isobutyl ketone (Merck f.s).
All solutions were prepared in $0.8 \mathrm{~mol} \mathrm{~L}^{-1}$ sulfuric acid. The reaction started after the addition of $10 \mathrm{~mL}$ of 0.182 mol L-1 $\mathrm{KBrO}_{3}$ to a solution containing $20 \mathrm{~mL}$ of $2.17 \mathrm{x}$ $10^{-3} \mathrm{~mol} \mathrm{~L}^{-1}(\mathrm{COOH})_{2}, 27 \mathrm{~mL}$ of $0.8 \mathrm{~mol} \mathrm{~L}^{-1} \mathrm{H}_{2} \mathrm{SO}_{4}, 1 \mathrm{~mL}$ of $0.029 \mathrm{~mol} \mathrm{~L}^{-1} \mathrm{Ce}\left(\mathrm{NO}_{3}\right)_{3}$ and $0.2 \mathrm{~mL}$ of a mixture of ketones for the oxalic acid oscillator.

For the $\mathrm{BZ}$ reaction with malonic acid, the reaction start after the addition of $10 \mathrm{~mL}$ of $0.182 \mathrm{~mol} \mathrm{~L}^{-1} \mathrm{KBrO}_{3}$ to a solution containing $40 \mathrm{~mL}$ of $2.17 \times 10^{-3} \mathrm{~mol} \mathrm{~L}^{-1}$ $\mathrm{CH}_{2}(\mathrm{COOH})_{2}, 7 \mathrm{~mL}$ of $0.8 \mathrm{~mol} \mathrm{~L}^{-1} \mathrm{H}_{2} \mathrm{SO}_{4}, 1 \mathrm{~mL}$ of 0.029 $\mathrm{mol} \mathrm{L}^{-1} \mathrm{Ce}\left(\mathrm{NO}_{3}\right)_{3}$ and $0.2 \mathrm{~mL}$ of a mixture of ketones

\section{Results and Discussion}

In the graphics of Figure 1, it is seen the effect of binary mixtures of ketones in the $\mathrm{BZ}$ reactions with oxalic acid.

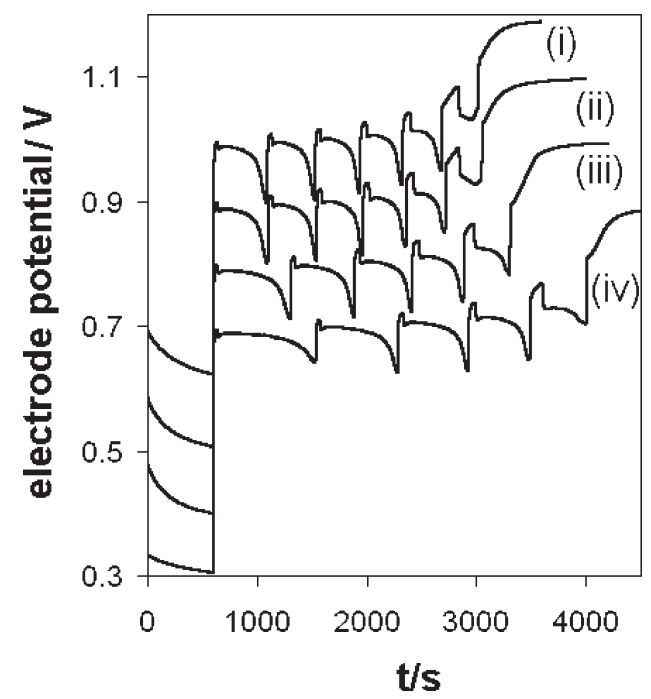

Figure 1. Effect of methyl-ethyl ketone, methyl-propyl ketone and methyl-isobutyl ketone in the reaction $\mathrm{BrO}_{3}-\mathrm{Ce}^{3+}-\mathrm{H}_{2} \mathrm{SO}_{4}-(\mathrm{COOH})_{2}-$ acetone. (i) pure acetone, (ii) acetone and methyl-ethyl ketone 1:1, (iii) acetone and methyl-propyl ketone $1: 1$, (iv) acetone and methyl-isobutyl ketone 1:1. To higher potentials an increase in the $\mathrm{Ce}(\mathrm{IV}) / \mathrm{Ce}(\mathrm{III})$ relation is expected.

In Figure 1 it is seen that replacing successively 50\% of the concentration of acetone in the initial $\mathrm{BZ}$ reaction with oxalic acid, for methyl-ethyl ketone, methyl-propyl ketone and methyl-isobutyl ketone, a lengthening of the period of each oscillation takes place. This is more evident in the first oscillation of the mixture with methyl-isobutyl ketone (Figure 1-iv). This behavior of the period of each oscillation is consistent with the order of enolization constant of each methyl ketone added. As the methylisobutyl ketone has the lowest enolization constant, the control that this ketone has over the $\mathrm{Br}_{2}$ concentration is not strong, permitting bromine to accumulate, and so, producing an induction period (Figure 2-i). Finally, Figure 


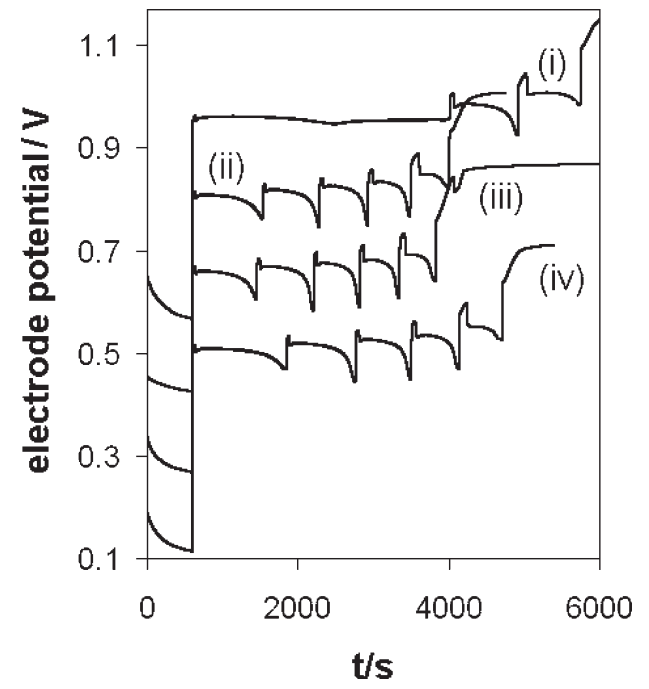

Figure 2. Effect of acetone, methyl-ethyl ketone and methyl-propyl ketone in the reaction $\mathrm{BrO}_{3}-\mathrm{Ce}^{3+}-\mathrm{H}_{2} \mathrm{SO}_{4}-(\mathrm{COOH})_{2}-$ $\left(\mathrm{CH}_{3}\right)_{2} \mathrm{CHCH}_{2} \mathrm{COCH}_{3}$ : (i) pure methyl-isobutyl ketone, (ii) acetone and methyl-isobutyl ketone 1:1, (iii) methyl-isobutyl ketone and methyl-ethyl ketone 1:1, (iv) methyl-isobutyl ketone and methylpropyl ketone 1:1.

1 shows that as we decrease the ketone's enolization constant, the amplitude of the oscillations remain approximately constant, the period of oscillations becomes larger, and at some point no oscillations will be observed. This bifurcation is related to the formation of a saddlenode on the limit cycle. ${ }^{12,13}$

In Figure 2 we see in some detail the transition from oscillations with no induction period to oscillations with induction period. The period of oscillations increases as we decrease the ketone's enolization constant and approach the bifurcation point, showing us again that there is a saddle node emerging on the limit cycle. The transitions from oscillatory to nonoscillatory regimes through a saddle-node is a characteristic feature of the oxalic acid-BZ oscillator. ${ }^{14,15}$

The BZ reaction with malonic acid does not need ketones to show an oscillatory behavior, but their presence change the global dynamics of the reaction. In this reaction, methyl ketones produce an enlargement in the induction period and an increment in the number of oscillations. The effect of methyl ketones in BZ reaction with malonic acid is proportional to the enolization constant of ketone, i.e., the effect is greater when acetone is used that when methyl-isobutyl ketone is used.

In Figure 3 it is shown that by adding pure acetone $\left(0.047 \mathrm{~mol} \mathrm{~L}^{-1}\right)$, the longest induction period is obtained, and it is reduced as $50 \%$ of the concentration of acetone is replaced successively by methyl-ethyl ketone, methylpropyl ketone and methyl-isobutyl ketone.

All these results predict that the effect of mixtures of methyl ketones in BZ type reactions is additive. Each of

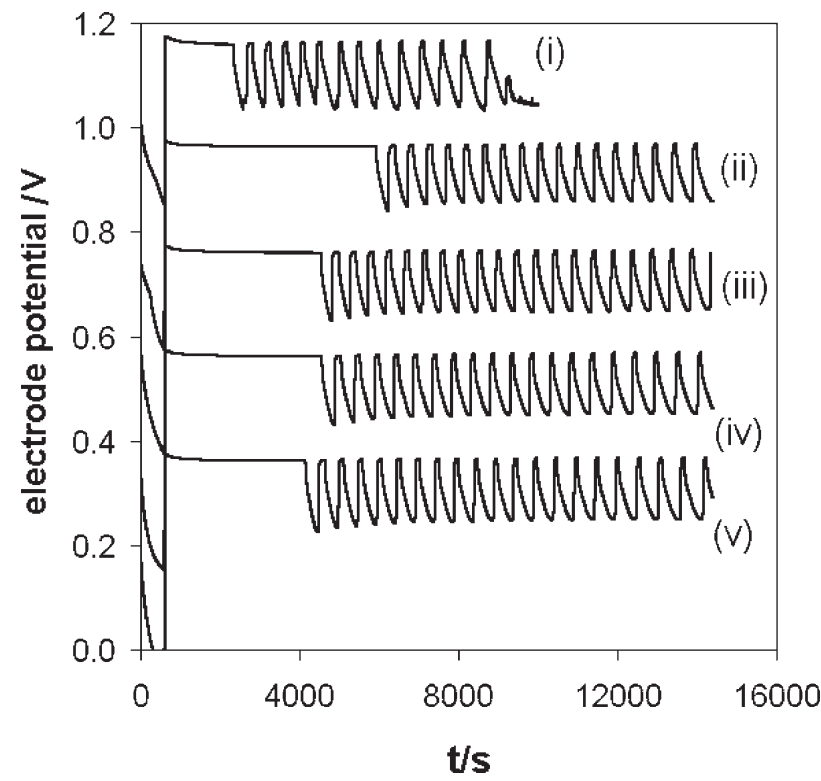

Figure 3. Effect of acetone, methyl-ethyl ketone, methyl-propyl ketone and methyl-isobutyl ketone in the $\mathrm{BrO}_{3}-\mathrm{Ce}^{3+}-\mathrm{H}_{2} \mathrm{SO}_{4}-$ $\mathrm{CH}_{2}(\mathrm{COOH})_{2}$ reaction. (i) $\mathrm{BZ}$ without ketone, (ii) $\mathrm{BZ}$ with acetone, (iii) $\mathrm{BZ}$ with acetone and methyl-ethyl ketone $1: 1$, (iv) $\mathrm{BZ}$ with acetone and methyl-propyl ketone 1:1, (v) BZ with acetone and methyl-isobutyl ketone 1:1.

the ketones acts independently in the reaction, producing one global effect over the reaction, wich is the sum of the effect of every ketone alone

In a previous work, ${ }^{10}$ we showed that the effect of methyl ketones, over the induction period in the BZ reaction with malonic acid, can be described by:

$$
\begin{aligned}
{\left[\mathrm{BrCH}(\mathrm{COOH})_{2}\right]_{\text {crucial }}=} & -\int_{0}^{\tau}\left(d\left[\mathrm{Br}_{2}\right] / d t\right) d t- \\
& \int_{0}^{\tau}\left(d\left[\mathrm{BrCH}_{2} \mathrm{COR}\right] / d t\right) d t
\end{aligned}
$$

Integrals on equation (1) are evaluated in the induction period interval. This equation can be read as follows: The time $\tau$ in which the crucial concentration of bromomalonic acid is reached depends on the kinetic competition between the integrated production of the molecular bromine in the reaction mixture and its integrated consumption by malonic acid and ketone. According to this equation the integrated production of brominated ketone $\left(\mathrm{BrCH}_{2} \mathrm{COR}\right)$ is going to lengthen the induction time.

As experimental results show, the effect of mixtures of methyl ketones is additive in the length of induction period and in the number of oscillations of $\mathrm{BZ}$ reaction with malonic acid. This way, we can generalize equation (1) :

$$
\begin{aligned}
{\left[\operatorname{BrCH}(\mathrm{COOH})_{2}\right]_{\text {crucial }}=} & -\int_{0}^{\tau}\left(d\left[\mathrm{Br}_{2}\right] / d t\right) d t- \\
& \sum_{1}^{n} \int_{0}^{\tau}\left(d\left[\mathrm{BrCH}_{2} \mathrm{COR}\right] / d t\right) d t
\end{aligned}
$$


The sum is made on the number of ketones that compose the mixture of methyl ketones in the reaction.

The validity of equation (2) is showed in the next section, since its inclusion in the numeric simulations allows us to reproduce the observed experimental behaviors.

\section{Simulations}

With the proposed mechanisms for the BZ reactions with oxalic acid and malonic acid, systems of coupled non-linear differential equations were built. These equations were integrated with a subroutine based upon Gear's algorithm. ${ }^{11}$ The methyl ketones in BZ reactions is included through the following reactions:

\section{$\mathrm{CH}_{3} \mathrm{COR}+\mathrm{H}^{+} \leftrightarrow \mathrm{CH}_{2}=\mathrm{COHR}+\mathrm{H}^{+}$}

Where for acetone $\mathrm{k}^{5} \mathrm{k}_{\text {forward }}=8.3 \times 10^{-5} \mathrm{~mol}^{-1} \mathrm{~L} \mathrm{~s}^{-1}$, for methylethyl ketone ${ }^{10} 7.3 \times 10^{-5} \mathrm{~mol}^{-1} \mathrm{~L} \mathrm{~s}^{-1}$, for methyl-propyl ketone ${ }^{10} \mathrm{k}=6.5 \times 10^{-5} \mathrm{~mol}^{-1} \mathrm{~L} \mathrm{~s}^{-1}$, for methyl-isobutyl ketone ${ }^{10} \mathrm{k}=5.3 * 10^{-5} \mathrm{~mol}^{-1} \mathrm{~L} \mathrm{~s}^{-1}$, and for $\mathrm{CH}_{2}=\mathrm{COHR}+\mathrm{Br}_{2}$ $\rightarrow \mathrm{BrCH}_{2} \mathrm{COR}+\mathrm{Br}^{-}+\mathrm{H}^{+}, \mathrm{k}=1.03 \times 10^{7} \mathrm{~mol}^{-1} \mathrm{~L} \mathrm{~s}^{-1} .5$

Simulations on Figure 4 are in good agreement with the experimental results obtained for BZ reaction with

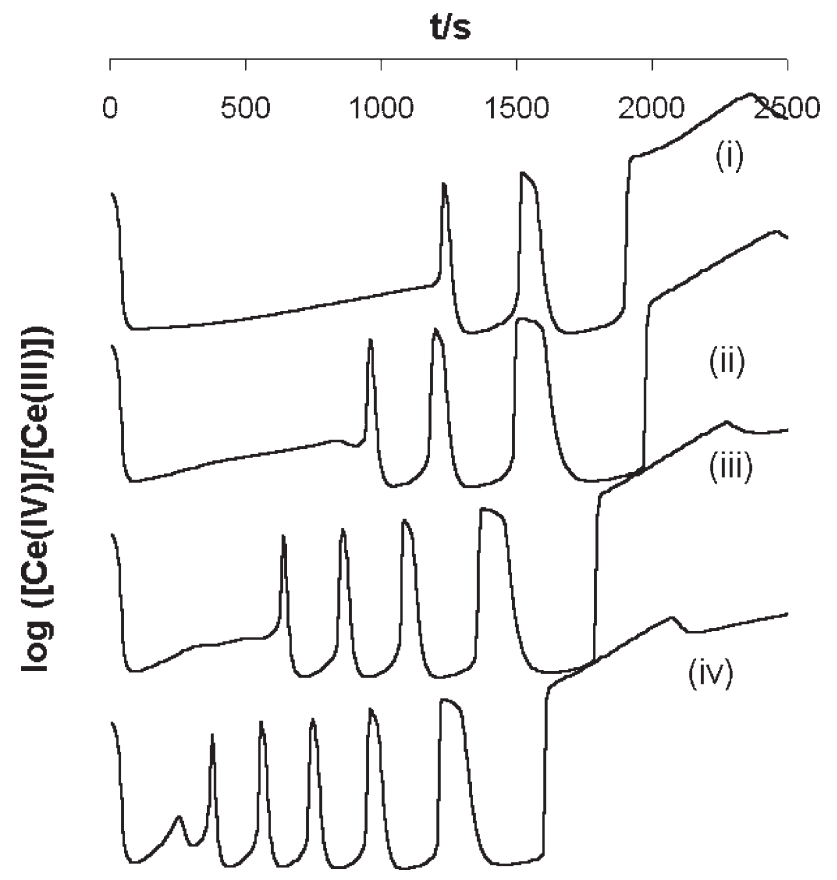

Figure 4. Simulations of the additivity of the effect of methyl ketones and mixtures of methyl ketones over the BZ reaction with oxalic acid and ketone. (i) pure methyl-isobutyl ketone; (ii) methylisobutyl ketone and methyl-propyl ketone 1:1; (iii) methyl-isobutyl ketone and methyl-ethyl ketone 1:1; (iv) methyl-isobutyl ketone and acetone 1:1.

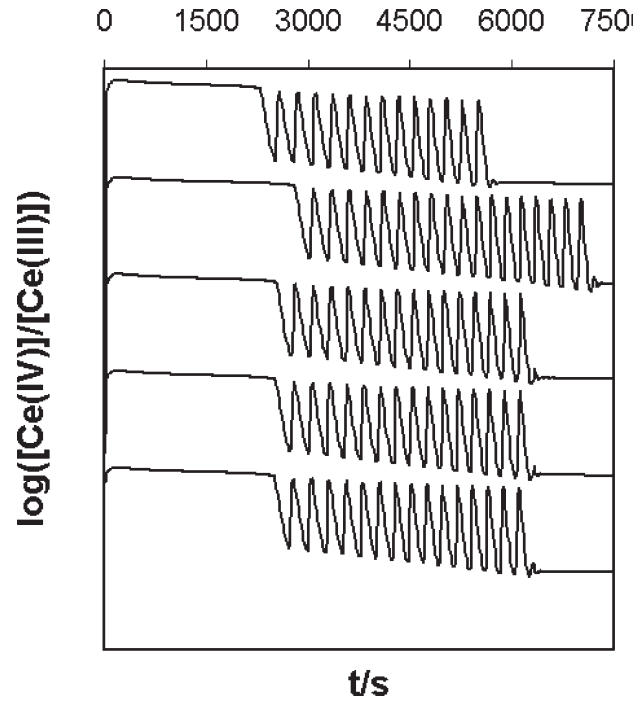

Figure 5. Simulations of the additivity of the effect of methyl ketones in mixtures on the $\mathrm{BZ}$ reaction with malonic acid. (i) without ketone, (ii) pure acetone, (iii) acetone and methyl-ethyl ketone 1:1, (iv) acetone and methyl-propyl ketone 1:1; (v) acetone and methylisobutyl ketone 1:1.

oxalic acid (Figure 2). It is seen that the length of the induction period present when pure methyl-isobutyl ketone is used (Figure 4-i), is shortened, proportionally, with the increases of enolization constant of the methyl ketone added.

Simulations in Figure 5 are also in good agreement with the results in Figure 3 for BZ reaction with malonic acid, where also it is seen that the enlargement or shortening of the induction period is proportional, respectively, to the enolization constant of the ketone added.

\section{Conclusions}

The effect of methyl ketones and mixtures of methyl ketones, on bromate driven oscillating reactions (Belousov-Zhabotinskii type), have an additive character. Each of the methyl ketones reacts with $\mathrm{Br}_{2}$, with a rate that is proportional to the value of their enolization constant. The global effect of a binary mixture of methyl ketones on the reaction dynamics, is the mean value between the ones that are observed for each of the pure methyl ketones.

For the classic BZ reaction the length of the induction period, in presence of binary mixtures of methyl ketones, can be explained under the crucial concentration of bromomalonic acid hypothesis, as it is showed in equation (2) in this work. For the oxalic acid oscillator it is associated with a mean value in the enol concentration. 


\section{References}

1. Belousov, B. P. In Oscillations and Travelling Waves in Chemical Systems; Field, R. J.; Burger, M., eds., Wiely: New York, 1985, p.605.

2. Epstein, I.; Pojman, J.; An Introduction to Nonlinear Chemical Dynamics, Oxford University Press: Oxford, 1998.

3. Field, R.; Burger, B.; Oscillations and Traveling Waves in Chemical Systems, Wiley: New York, 1985, p. 69.

4. Berenstein, I.; Agreda J.; Barragán, D.; Phys. Chem. Chem. Phys (PCCP) 1999, 1,4601.

5. Field R.; Boyd, P.; J. Phys. Chem. 1985, 89, 3707.

6. Field, R.; Koros, E.; Noyes, R.; J. Am. Chem. Soc. 1972, 94, 8649.

7. Gyorgyi, L.; Turanyi, T.; Field, R.; J. Phys. Chem. 1990, 94, 7162.
8. Turanyi, T.; Gyorgyi, L.; Field, R.; J. Phys. Chem. 1993, 97, 1931

9. Burger, M.; Koros, E.; J. Phys. Chem. 1980, 84, 496.

10. Berenstein, I.; Agreda, J.; Barragán, D.; J. Phys. Chem. A. 1999, 103, 970.

11. Hindmarsh, C.; Gear: Ordinary Differential Equation Solver, Technical report No. UCID-3001, Rev. 2, Lawrence Livermore Laboratory, 1972. Based upon Gear, C.W.; Commun. ACM. 1971, 14, 185

12. Mazelko, J.; Chem. Phys. 1982, 67, 17.

13. Mazelko, J.; Chem. Phys. 1983, 78, 381.

14. Noszticzius, Z.; Stirling, P.; Wittman, M.; J. Phys. Chem. 1985, $89,4974$.

15. Gaspar, V.; Galambosi, P.; J. Phys. Chem. 1986, 90, 2222.

Received: January 19, 2004

Published on the web: October 15, 2004 